\title{
Biomarkers improves prognostic and mortality prediction in pneumonia
}

\author{
D. Danis Vijay ${ }^{1}$, S. Jayanthi ${ }^{2, *}$, N. Meenakshi ${ }^{3}$ \\ 1 Junior Research Fellowship, ${ }^{2}$ Professor, ${ }^{3}$ Professor and HOD, ${ }^{1,2}$ Dept. of Microbiology, ${ }^{3}$ Dept. of Respiratory Medicine, \\ Chettinad Academy of Research and Education Chettinad Hospital and Research Institute, Tamil Nadu, India
}

\author{
*Corresponding Author: S. Jayanthi \\ Email: jayanthitan@gmail.com
}

Received: $22^{\text {nd }}$ July, 2018

Accepted: $26^{\text {th }}$ November, 2018

\begin{abstract}
Pneumonia exhibits mortality rates, between $20 \%$ and $50 \%$ in severe cases. Biomarkers are useful tools for antibiotic therapy modifications as well as diagnosis, prognosis and follow-up treatment of pneumonia. This review presents the biological and clinical features of various biomarkers in Pneumonia patients, including C-reactive protein, Procalcitonin, Coceptin, D-dimers, MRpro-ADM, (Mid-regional pro adrenomedullin), Corisol, Endothelin-1, Soluble Triggering Receptor Expressed on Myeloid Cells-1 (sTREM-1), Adrenomedullin, Endotoxin, Mid regional Pro-Atrial Natriuretic Peptide (MR-proANP), TNF- $\alpha$ Polymorphisms, Pentraxin 3.
\end{abstract}

Keywords: Pneumonia, Community-acquired, Hospital-acquired, Ventilator-associated pneumonia (VAP), Biomarkers, Point of care testing.

\section{Introduction}

Pneumonia, one of the most common infectious diseases, associated with high morbidity and mortality worldwide. ${ }^{1}$ Pneumonia is one of the cause of death in children, killing more than 2,500 children a day globally and $7 \%$ of all deaths in adults. ${ }^{2}$

Pneumonia is considered to be the most prevalent cause of sepsis associated with the highest mortality rates. ${ }^{1}$ Since infectious diseases are related to immunemediated disorders, genetic susceptibility loci for immune traits can be considered as good candidates in genetic association studies of pneumonia and its complications. $^{3}$

Pneumonia is classified according to the site of acquisition as community-acquired (CAP) and hospitalacquired (or nosocomial) pneumonia (HAP or NP), which includes healthcare-associated pneumonia (HCAP) and ventilator-associated pneumonia (VAP). HAP tends to be a more serious problem than CAP, since HAP patients have an increased risk of infection caused by antibiotic-resistant organisms, besides they are often burdened by comorbidities.

The first line of defence of the innate immune system is represented by pattern-recognition receptors that sense bacterial, viral or fungal molecular structures and induce systemic inflammation. Various ongoing research is being done in this field so as to put an array of biomarkers at the disposal of doctors to improve the diagnosis of pneumonia when patients present to them with cough or nonspecific symptoms which could easily be misinterpreted as symptoms of other conditions.

Some biomarkers which are still being studied for their feasible use in pneumonia; these include endotoxin, proadrenomedullin, procalcitonin soluble triggering receptor expressed on myeloid cells-1, C- reactive protein, leukocyte count, and pro inflammatory cytokines. An optimal biomarker for bacterial pulmonary infections should grant a rapid diagnosis, have a prognostic value and expedite therapeutic determination making. The two biomarkers currently in clinical use are C-reactive protein and procalcitonin. Creactive protein is very unspecific and elevated in bacterial as well as viral infections. ${ }^{4}$

\section{Procalcitonin}

The peptide PCT is a prohormone of the active hormone calcitonin that is synthesized in the C-cells of the thyroid. PCT is encoded by the CALC-I gene. ${ }^{5}$ Microbial toxins and proinflammatory mediators (IL$1 \beta$, TNF- $\alpha$, IL-6) induce a significant increase of PCT release from parenchymal organs. Increased PCT concentrations are detectable within $2 \mathrm{~h}$ of an infectious bacterial stimulus, which is a more prompt increase compared with CRP, but slower when compared with cytokines biomarkers.

PCT levels are not elevated in viral infections, because in contrast to bacterial infections a viral infection does not lead to a ubiquitous increase of $C A L C$ - 1 gene expression and a constitutional release of PCT from entire parenchymal tissues and extricate cell types around the body. In a meta-analysis of hospitalized patients, PCT has higher sensitivity and specificity when compared with CRP in the differential diagnosis of bacterial infections from noninfectious causes of inflammation. PCT also shows a higher sensitivity to differentiate between viral and bacterial infections. ${ }^{6}$

Anokhi et $\mathrm{al}^{7}$ (2016) as reported that PCT biomarker had area under curve of about 0.79 with the cut off range 1 to $1.25 \mathrm{ug} / \mathrm{ml}$. The sensitivity and specificity about $80 \%$ and $96 \%$ respectively which is 
statistically significant $(\mathrm{p}<0.001)$. A Nicola et $\mathrm{al}^{2}$ in 2017 as reported that PCT biomarker had Area under curve of about 0.04 . The sensitivity and specificity was found to be $95 \%$ and $100 \%$ respectively which is statistically significant $(\mathrm{p}<0.001) .{ }^{8}$ [Table 1] \& [Fig. 1]

Table 1: Shown biomarkers in various studies \& their AUC

\begin{tabular}{|l|c|c|c|c|}
\hline \multicolumn{1}{|c|}{$\begin{array}{c}\text { (Biomarker) } \\
\text { PCT }\end{array}$} & $\begin{array}{c}\text { AUC } \\
(\mathbf{9 5 \%} \text { CI) }\end{array}$ & $\begin{array}{c}\text { \% Sensitivity } \\
\text { Range (No. } \\
\text { studies)(95\% CI) }\end{array}$ & $\begin{array}{c}\text { \% Specificity } \\
\text { Range (No. } \\
\text { studies) (95\% CI) }\end{array}$ & P-Value \\
\hline Anokhi $^{7}$ et al 2016 & 0.79 & $80 . \%$ & $96 \%$ & 0.001 \\
\hline Nicola $^{2}$ et al 2017 & 0.04 & $95 \%$ & $100 \%$ & 0.001 \\
\hline sTERM-1 & \multicolumn{5}{|l|}{} \\
\hline Anokhi J7 et al 2016 & 0.082 & $53.2 \%$ & $86.3 \%$ & 0.001 \\
\hline Yuetian $^{14}$ et al 2017 & 0.0831 & $85.5 \%$ & $73.1 \%$ & 0.05 \\
\hline MRpro-ADM $^{\text {SR Akpinar }}{ }^{20}$ et al 2014 & 0.513 & $66.7 \%$ & $86.8 \%$ & $<0.001$ \\
\hline Bello $^{8}$ et al 2012 $^{\mid}$ & 0.851 & $92.1 \%$ & $55.1 \%$ & $<0.001$ \\
\hline
\end{tabular}

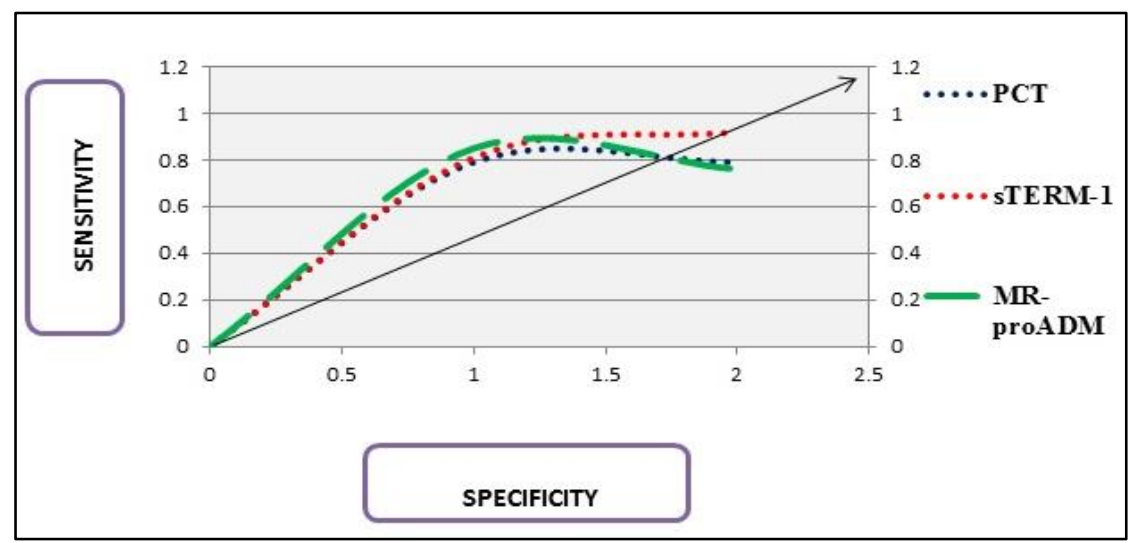

Fig. 1: AUC curves for the biomarkers used in respiratory failure

The AUC curves shown are the PCT,s TERM-1. MR-pro. ADM

\section{Soluble Triggering Receptor Expressed on Myeloid Cells-1 (sTREM-1)}

Soluble Triggering receptor expressed on myeloid cells-1 (TREM- 1) is another biomarker which holds great promise when it comes to pneumonia. sTREM-1 belongs to the immunoglobin superfamily and is involved in inflammatory response. ${ }^{9}$

It has the advantage of being increased during infectious processes but not in noninfectious inflammatory conditions like psoriasis, ulcerative colitis, and vasculitis. STREM-1 exists in both amembranous and a soluble form(soluble triggering receptor expressed on myeloid cells-1; sTREM-1). ${ }^{10}$ altitude of sTREM-1 have been create to be exalted in bronchoalveolar lavage fluids of patients with pneumonia, in the plasma of septic patients, and in the exhaled breath condensate in VAP patients. ${ }^{11}$

Gibot $^{11}$ study documents sTREM-1 levels $\geq$ $5 \mathrm{pg} / \mathrm{mL}$ in bronchoalveolar lavage fluids (BAL), they approximate to $100 \%$ of VAP patients, 95\% CAP patients and only $10 \%$ patients without pneumonia. A cut-off value of $5 \mathrm{pg} / \mathrm{mL}$ had a sensitivity of $98 \%$ and a specificity of $90 \%$ to predict pneumonia. ${ }^{12}$ However, no significant difference has been found in the levels obtained from CAP and VAP patients.

In patients who developed VAP, sTREM-1 levels in BAL were found to start rising 6 days prior to VAP diagnosis. sTREM- Early treatment can be started in VAP patients when sTREM-1 is used. Furthermore, Gibot et al. stated that combined measurement of serum PCT and BAL STREM-1 can be useful in differentiating VAP from extrapulmonary infection. ${ }^{13}$

Anokhi et $\mathrm{al}^{7}$ (2016) as reported that sTERM-1 biomarker had Area under curve of about 0.082 with the cut off range $755 \mathrm{pg} / \mathrm{ml}$. The sensitivity and specificity was found to be $53.2 \%$ and $86.3 \%$ respectively and statistically significant $(p<0.001)$. Youtian et $\mathrm{al}^{14}$ (2017) as reported that sTERM-1 biomarker had Area under curve of about 0.0831 with the cut off range $23.61 \mathrm{ug} / \mathrm{ml}$. The sensitivity and specificity was found to be $85.5 \%$ and $73 \%$ respectively which is statistically significant $(\mathrm{p}<0.05)$ with $\mathrm{r}$ - ratio0.78. [Table 1]

\section{Mid-regional Proadrenomedullin}

Human adrenomedullin (ADM) is a 52-amino acid peptide that is synthesized as part of pre-pro- 
adrenomedullin, a larger precursor molecule. ${ }^{15}$ This peptide is a secretory product of the vascular endothelium, the ADM gene is expressed in a wide range of tissues but initial studies on the distribution of this gene have suggested that the highest levels of expression are observed in the adrenal medulla, ventricular chambers, kidneys and lungs. ${ }^{16}$ MR-pro$\mathrm{ADM}$ is a stable, functionally irrelevant fragment of ADM degradation that is used in some studies because of its better technical viability. ${ }^{16}$

The ADM levels upon admission were significantly higher in the patients who died during the follow-up compared to the patients who survived: 2.1 $(1.5-3.0 \mathrm{nmol} / \mathrm{L})$ vs. $1.0(0.6-1.6 \mathrm{nmol} / \mathrm{L})(\mathrm{p}, 0.001)$. An analysis of the "treatment failure" and "death" outcomes demonstrated that the prognostic accuracy of ADM was similar to the PSI score but higher than other parameters. ${ }^{17}$

$\mathrm{R}$ Cavallazzi et $\mathrm{al}^{18}-2014$ in his study proved elevated MR-proADM was associated with an increase in short-term mortality (OR Z 6.8; 95\% CI: 4.65e10.13; $P$ value $<0.001$ ) and complications (OR Z 5.0; 95\% CI: 3.86 to $6.49 ; \mathrm{P}$ value $<0.001)$. The sensitivity ranged from 0.62 to 0.80 , while the specificity ranged from 0.53 to 0.86 . [Table 1]

According to $\mathrm{S}$ Akpinar et al ${ }^{19} 2014$, the values of area under the ROC curve for each parameter MRproADM AUC, area under the curve; 0.513, Standard error 0.081, P-value $\mathrm{P}<0.001 \mathrm{MR}-\mathrm{ProADM}$ and PSI combination had $92.1 \%$ specificity and $50.1 \%$ sensitivity to predict mortality in 4 weeks. When MRproADM and Pneumonia Severity Index (PSI) combination showed $71 \%$ specificity and $84 \%$ sensitivity to expect 8-week mortality.

\section{D-dimers}

D-dimers are released into the blood during the dissolution process of fibrin emboli in the fibrinolytic system. D-dimers are the smallest fragments of the fibrin degradation, and these proteins are detectable in blood plasma.

The most important application of D-dimers is related to thrombotic events. D-dimers have been studied extensively as a diagnostic method for deep vein thrombosis (DVT) and pulmonary embolism (PE). ${ }^{20} \mathrm{~A}$ negative result has diagnostic utility that is comparable to normal lung scans or negative duplex ultrasound findings. ${ }^{21}$ The application of the D-dimers analysis to CAP is a novel approach.

According to Fruchter et $\mathrm{al}^{22}$ and Jose. M et al Ddimer biomarker had area under curve 0.0862 and 0.78 cut off range $1.52 \mu \mathrm{g} / \mathrm{ml}$ and $0.91 \mu \mathrm{g} / \mathrm{ml}$ respectively. A Karalezli et $\mathrm{al}^{23}(2009)$ as reported that D-dimer biomarker had Area under curve of about 0.82. The sensitivity and specificity were $60.2 \%$ and $94.2 \%$ respectively which was statistically significant $(\mathrm{p}<0.001)$. [Table 2]

Jose. $\mathrm{M}$ et $\mathrm{al}^{24}$ as reported that $\mathrm{D}$-dimer biomarker had Area under curve of about 0.86 with the cut off range $0.91 / \mathrm{ml}$. The sensitivity and specificity was found to be high about $97.4 \%$ and $98.1 \%$ respectively which is statistically significant $(\mathrm{p}<0.001)$. [Fig. 2]

Table 2: Area under curve values for D-dimer, Endotoxin, TNF- a, Pentraxin-3.

\begin{tabular}{|c|c|c|c|}
\hline \multicolumn{4}{|c|}{ Area Under Curve Values Based On Different Biomarkers } \\
\hline Author & Biomarker & AUC Values & P-values \\
\hline O Fruchter et $\mathrm{al}^{38}$ & D-dimer & 0.086 & $p<0.011$ \\
\hline Jose $\mathrm{M}$ et $\mathrm{al}^{24}$ & D-dimer & 0.86 & $\mathrm{p}<0.001$ \\
\hline Ledox D et $\mathrm{al}^{28}$ & Endotoxin & 0.92 & $\mathrm{p}<0.001$ \\
\hline Kilmiec E et al ${ }^{29}$ & Endotoxin & 4.23 & $\mathrm{p}<0.001$ \\
\hline Menedez $\mathrm{R}$ et $\mathrm{al}^{37}$ & TNF- $\alpha$ & 0.88 & $p<0.001$ \\
\hline Kao SJ et al ${ }^{41}$ & Pentraxin-3 & 0.29 & $\mathrm{p}<0.001$ \\
\hline Tommaso et $\mathrm{al}^{42}$ & Pentraxin-3 & 0.82 & $\mathrm{p}<0.001$ \\
\hline
\end{tabular}

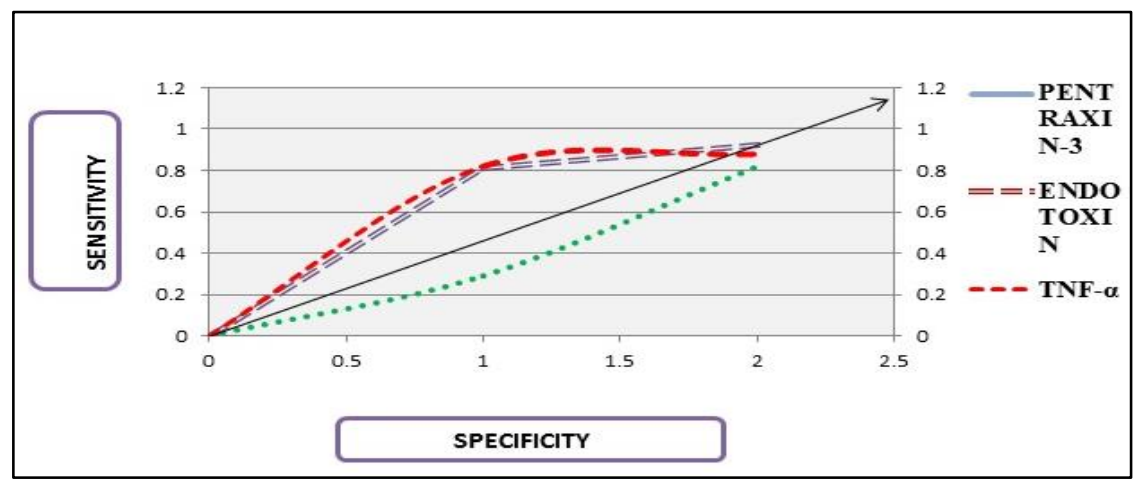

Fig. 2: AUC curves for the biomarkers used in respiratory failure The AUC curves shown are the pentrasin-3, Endotoxin, TNF- $\alpha$ 


\section{Endotoxin}

Endotoxin measurements in BAL showed a relation between its concentration and the quantity of Gram-negative bacteria in BAL fluids of VAP patients. Endotoxin allows rapid diagnosis of Gram-negative bacterial pneumonia. ${ }^{25}$

Flanagan et al found that endotoxin level within four days of starting mechanical ventilation is an accurate as well as a rapid way for diagnosing VAP. ${ }^{26}$ In a study conducted by Nys $\mathrm{M}$ et al., it was established that antimicrobial Gram-negative therapy may be justified according to the results of endotoxin level in BAL fluids of ventilated patients having pneumonia. ${ }^{27}$

Ledox D et $\mathrm{al}^{28}$ reported that Endotoxin biomarker had Area under curve of about 0.92 . The sensitivity and specificity were $82.2 \%$ and $95.6 \%$ respectively which is statistically significant $(p<0.001)$. [Fig. 2] Kilmiec E et $\mathrm{al}^{29}$ in 2018 has documented that Endotoxin biomarker had Area under curve of about 4.23. The sensitivity and specificity were $93 \%$ and $95 \%$ and statistically significant $(\mathrm{p}<0.001)$ [Table 2].

\section{TNF- $\alpha$ Polymorphisms}

TNF- $\alpha$ is a potential proinflammatory cytokine that plays a critical role in inflammatory and immune responses. Excessive TNF- $\alpha$ production contributed to lung injury in a variety of diseases ${ }^{30,31}$ and increased the risk of sepsis. ${ }^{32}$ Furthermore, Puren et $\mathrm{al}^{36}$ As a biomarker, levels of TNF- $\alpha$ in plasma indicates the severity of pneumonia. ${ }^{47}$

In mechanically ventilated patients, Montón and colleagues found that serum TNF- $\alpha$ level was significantly higher in patients with pneumonia compared with controls. ${ }^{33}$ In addition, Bauer et al. showed that levels of serum TNF- $\alpha$ was strongly associated with the degree of lung injury. ${ }^{34,35}$

According to Kilmiec et al, ${ }^{29}$ TNF- $\alpha$ sensitivity and specificity were $93 \%$ and $95 \%$ respectively statistical significance $\mathrm{P}<0.03$. Menede et a ${ }^{37}$ reported that TNF- $\alpha$ biomarker had Area under curve of about 0.88 . The sensitivity and specificity about $95 \%$ and 98\% and statistically significant $(\mathrm{p}<0.001)$ [Table 2]

\section{Pentraxin 3}

In Bronchoalveolar lavage fluid PTX3 levels and diagnosis of pneumonia represents one of the most widespread infections in intubated ICU patients and is associated with significant morbidity (for example, prolonged mechanical ventilation, end-stage organ failure), costs and mortality. ${ }^{38}$ Timely and accurate diagnosis of pneumonia is crucial to starting appropriate treatment and improving patients' recovery and survival. However, to date, a rapid and accurate approach to diagnose pneumonia in intubated critically ill patients is lacking. ${ }^{39}$

In the subset of patients, pretest probability was higher and the diagnostic accuracy of a screening test such as PTX3 was expected to be poorer and oxygenation did not differ between infected and uninfected patients. Other studies have proved that plasma PTX3 level is correlated with the severity of ARDS. ${ }^{40}$

Earlier in 2013 Kao SJ et $\mathrm{al}^{41}$ reported that Penraxin-3 biomarker had Area under curve of about 0.290 . The sensitivity (85\%) and specificity (93\%) and statistically significant $(\mathrm{p}<0.001)$ [Fig. 2]. In 2015 Tommaso et $\mathrm{al}^{42}$ as reported that Penraxin-3 biomarker had Area under curve of about 0.827 . The sensitivity $(92 \%)$ and specificity $(60 \%)$ and statistically significant $(\mathrm{p}<0.001)$.

\section{Disadvantages}

Today, no biomarker is sensitive enough in LRTI to definitely exclude bacterial infection. And it is not possible to withhold an antibiotic therapy in a critically ill patient with suspected severe respiratory infection on the basis of a single measurement of a biomarker. If the biomarker values remain unremarkable or low at follow-up measurements, a relevant severe infection is very unlikely. ${ }^{43}$

Earlier study done by documents even the PCTguided antimicrobial escalation strategy with daily measurements of PCT in the ICU were not superior to a standard strategy of antimicrobial escalation and did not improve survival. ${ }^{44}$ Thus, in the ICU setting PCT is valuable for the management of de-escalation but not escalation of antibiotic therapy.

Advantages: Biomarkers show improved validation in the diagnosis of pulmonary infections than, imaging techniques. ${ }^{45}$ Biomarkers can also be used in a broad setting as a point-of-care diagnostic and without any risk to the patient compared with radiation exposure during chest x-ray or computed tomography. The serial measurements of biomarkers can reflect the dynamics of CAP. ${ }^{46}$ They are a useful tool to monitor resolution of Pneumonia, which goes along with a decrease in elevated biomarker levels.

\section{Conclusion}

Biomarkers are used as Point-of-care tests in emergency rooms and out patients department. Clinicians can make real-time decisions about the care and the admission path of patients. Once there is a complete understanding of all the information that can be gained from these simple tests, there will be greater insight into the future management of patients with Pneumonia.

The combination of several biomarkers reflecting different pathophysiological aspects of Pneumonia, such as PCT for bacterial infection and Pentraxin 3, MRproADM for inflammation and circulation, could offer future potential for improved management in Pneumonia. In near future biomarkers will reflects in improved patients outcome.

\section{Conflict of Interest: None}




\section{Key Issues}

1. Procalcitonin (PCT) improves the diagnosis of clinically-relevant bacterial pulmonary infections compared with C-reactive protein or leukocytes.

2. In lower respiratory tract infections in general a PCT-guided algorithm significantly reduces antibiotic exposure without a negative influence on clinical outcome compared with standard therapy.

3. Inflammatory biomarkers are not helpful for the individual diagnosis of microbiological etiology of pneumonia.

4. In Pneumonia, cardiovascular biomarkers have a higher prognostic value compared with inflammatory biomarkers.

\section{Reference}

1. Mayr. Epidemiology of severe sepsis. Virulence. 2014;5:4-11.

2. Nicola Principi. Biomarkers in Pediatric CommunityAcquired Pneumonia. Int J Mol Sci. 2017;18(2)447. doi:10.3390/ijms18020447

3. Kumar. Genetics of immune-mediated disorders: from genome-wide association to molecular mechanism. Curr Opin Immunol. 2014;31:51-57.

4. Stefan Krüger. Biomarkers in Community-acquired Pneumonia. Expert Rev Resp Med. 2012;6(2):203-214.

5. Müller B., Markers of acute inflammation in assessing and managing lower respiratory tract infections: focus on procalcitonin. Clin. Microbiol. Infect. 2006;12:8-16.

6. Simon L. Serum procalcitonin and C-reactive protein levels as markers of bacterial infection: a systematic review and meta-analysis. Clin. Infect. Dis. 2004;39(2):206-217.

7. Anokhi J. Host Biomarkers for Distinguishing Bacterial from Non-Bacterial Causes of Acute Febrile Illness: A Comprehensive Review. PLOS ONE. 11(8): e0160278. doi:10.1371/journal.pone.0160278.2016

8. S Bello. Prognostic power of proadrenomedullin in community-acquired pneumonia is independent of aetiology. Eur Respir J. 2012;39:1144-1155. DOI: 10.1183/09031936.00080411.

9. G.J. Soto. Diagnostic strategies for nosocomial pneumonia. Current Opinion in Pulmonary Medicine. 2007;13(3):186-191.

10. J. Phua. Soluble triggering receptor expressed on myeloid cells- 1 in acute respiratory infections. European Respiratory Journal. 2006;28(4):695-702.

11. S Gibot. Soluble Triggering Receptor Expressed on Myeloid Cells and the Diagnosis of Pneumonia. N Eng $l J$ Med. 2004;350:451-8.

12. A. Cravoisy., Soluble form of the triggering receptor expressed on myeloid cells- 1 as a marker of microbial infection. Clinical Medicine \& Research. 2004;2(3):181187.

13. R. Dupays. Combined measurement of procalcitonin and soluble TREM-1 in the diagnosis of nosocomial sepsis. Scandinavian Journal of Infectious Diseases. 2007;39(67):604-608.

14. Yuetian Yu. Diagnostic Performance of Soluble Triggering Receptor, Expressed on Myeloid Cells-1 in Ventilator-Associated Pneumonia of Patients with Ischemic Stroke. Canadian Journal of Infectious Diseases and Medical Microbiology. 2017, Article ID 9513690, doi.org/10.1155/2017/9513690.
15. Ishimitsu T. Genomic structure of human adrenomedullin gene. Biochem Biophys Res Commun. 1994;203(1):631-9. doi.org/10.1006/ bbrc.1994.2229.

16. Kitamura K. Cloning and characterization of cDNA encoding a precursor for human adrenomedullin. Biochem Biophys Res Commun. 1993;194(2):720-5. doi.org/10.1006/bbrc.1993.1881

17. Sugo S. Endothelial cells actively synthesize and secrete adrenomedullin. Biochem Biophys Res Commun. 1994;201(3):1160-6. doi.org/ 10.1006/bbrc.1994.1827

18. Nishio K. Increased plasma concentrations of adrenomedullin correlate with relaxation of vascular tone in patients with septic shock. Crit Care Med. 1997;25(6):953-7. doi.org/10.1097/00003246199706000-00010.

19. R Cavallazzi. Midregional proadrenomedullin for prognosis in community-acquired pneumonia: A systematic review, Respiratory Medicine. 2014;108:1569e-1580.

20. Serdar Akpinar. Performance evaluation of MRproadrenomedullin and other scoring systems in severe sepsis with pneumonia. J Thorac Dis. 2014;6(7):921-929.

21. Salluh JI. Adrenal response in severe communityacquiredpneumonia: impact on outcomes and disease severity. Chest. 2008;134(5):947-54. doi.org/10.1378/chest.08-1382.

22. Kelly J. Plasma D-dimers in the diagnosis of venous thrombo embolism. Arch Intern Med. 2002;162(7):74756. doi.org/10.1001/archinte.162.7.747.

23. A Karalezli. Cut-off value of D-dimer in pulmonary thromboembolism and pneumonia. Turk J Med Sci. 2009;39(5):687-692. c TUBİTAK, doi:10.3906/sag-09039 .

24. Jose M. Plasma d-Dimer Levels Correlate with Outcomes in Patients With Community- Acquired Pneumonia, CHEST. 2004;126:1087-1092.

25. Q Ribelles. Plasma d-dimer levels correlate with outcomes in patients with community-acquired pneumonia. Chest. 2004;126(4):1087-92. doi.org/10.1378/chest.126.4.1087.

26. J. Pugin. Rapid diagnosis of gram negative pneumonia by assay of endotoxin in bronchoalveolar lavage fluid. Thorax. 1992;47(7):547-549.

27. P.G. Flanagan. Diagnosis of Gram negative, ventilator associated pneumonia by assaying endotoxin in bronchial lavage fluid. Journal of Clinical Pathology. 2001;54(2):107-110.

28. Ledoux D. Correlation between endotoxin level and bacterial count in broncho alveolar lavage fluid of ventilated patients.

29. Kilmiec E. Reduced release of TNF $\alpha$ and IP-10 after exvivo blood stimulation with endotoxin is associated with poor outcome after stroke. 2018;102:51-54. doi: 10.1016/j.cyto.2017.12.015.

30. L.K. Morrison. Utility of a rapid B-natriuretic peptide assay in differentiating congestive heart failure from lung disease in patients presenting with dyspnea. Journal of the American College of Cardiology. 2002;39(2):202209.

31. Wright TW. TNF receptor signaling contributes to chemokine secretion, inflammation, and respiratory deficits during Pneumocystis pneumonia. J Immunol. 2004; 172:2511- 2521.

32. Hildebrandt GC. Donor-derived TNF-a regulates pulmonary chemokine expression and the development of idiopathic pneumonia syndrome after allogeneic bone marrow transplantation. Blood. 2004;104:586-593. 
33. Teuffel. Association between tumor necrosis factor[alpha] promoter-308 $\mathrm{A} / \mathrm{G}$ polymorphism and susceptibility to sepsis and sepsis mortality: A systematic review and meta-analysis. Crit Care Med. 2010;38:276282.

34. Montón C. (1999) Cytokine expression in severe pneumonia: a broncho alveolar lavage study. Crit Care Med. 1999;27:1745-1753.

35. Bauer TT. Comparison of systemic cytokine levels in patients with acute respiratory distress syndrome, severe pneumonia, and controls. Thorax. 2000;55:46-52.

36. Puren AJ, Feldman C, Savage N, Becker PJ, Smith C. Patterns of cytokine expression in community-acquired pneumonia. Chest. 1995;107:1342-1349.

37. Menéndez R. Biomarkers improve mortality prediction by prognostic scales in communityacquired pneumonia, 2009;64(7):587-91. doi: 10.1136/thx.2008.105312

38. O Fruchter. D-dimer as a Prognostic Biomarker for Mortality in Chronic Obstructive Pulmonary Disease Exacerbation, D-dimer as a Prognostic Biomarker for Mortality in Chronic Obstructive Pulmonary Disease Exacerbation. Am J Med Sci. 2015;349(1):29-35.

39. American Thoracic Society, Infectious Disease Society of America: Guidelines for the management of adults with hospital-acquired, ventilator-associated, and healthcareassociated pneumonia. Am J Respir Crit Care Med. 2005; 171:388-416.

40. Horan TC. Surveillance definition of health careassociated infection and criteria for specific types of infections in the acute care setting. Am J Infect Control. 2008;36:309-332. A published erratum appears in Am J Infect Control. 2008;36:655.

41. Kao SJ. Plasma long pentraxin 3 (PTX3) concentration is a novel marker of disease activity in patients with community-acquired pneumonia. 2013;51(4):907-13. doi: 10.1515/cclm-2012-0459.

42. Tommaso, Pentraxin 3 in acute respiratory distress syndrome: An early marker of severity. Crit Care Med. 2008;36(8). DOI: 10.1097/CCM.0b013e3181809aaf.

43. Mauri. Pentraxin 3 in acute respiratory distress syndrome: an early marker of severity. Crit Care Med. 2008;36:2302-2308.

44. Greenwald JL. Procalcitonin algorithms for antibiotic therapy decisions: a systematic review of randomized controlled trials and recommendations for clinical algorithms. Arch Intern Med. 2011;171(15):1322-1331.

45. Jensen JU. Procalcitonin-guided interventions against infections to increase early appropriate antibiotics and improve survival in the intensive care unit: a randomized trial. Crit. Care Med. 2011;39;2048-2058.

46. Schuetz P., Procalcitonin-Guided Antibiotic Therapy and Hospitalisation in Patients with Lower Respiratory Tract Infections (ProHOSP) study group. Prognostic value of procalcitonin in community-acquired pneumonia. Eur Respir J. 2011;37:384-392.

How to cite this article: Vijay D. D, Jayanthi S, Meenakshi N. Biomarkers improves prognostic and mortality prediction in pneumonia. Indian $\mathbf{J}$ Microbiol Res. 2018;5(4):430-435. 